\title{
Is Primary Aldosteronism Still Largely Unrecognized?
}

Authors

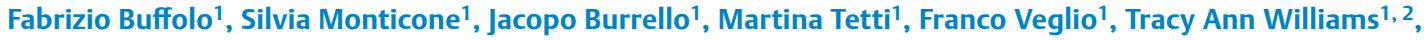
Paolo Mulatero ${ }^{1}$

\author{
Affiliations \\ 1 Division of Internal Medicine and Hypertension Unit, \\ Department of Medical Sciences, University of Torino, \\ Torino, Italy \\ 2 Medizinische Klinik und Poliklinik IV, Klinikum der \\ Ludwig-Maximilians-Universität München, Munich, \\ Germany
}

Key words

aldosterone, primary aldosteronism, aldosterone producing adenoma, bilateral adrenal hyperplasia

received 03.08 .2017

accepted 06.09.2017

\author{
Bibliography \\ DOI https://doi.org/10.1055/s-0043-119755 \\ Published online: 16.11.2017 \\ Horm Metab Res 2017; 49: 908-914 \\ (c) Georg Thieme Verlag KG Stuttgart · New York \\ ISSN 0018-5043 \\ Correspondence \\ Paolo Mulatero MD \\ Division of Internal Medicine and Hypertension \\ Department of Medical Sciences \\ University of Torino \\ Via Genova 3
}

\author{
10126 Torino \\ Italy \\ Tel.: + 39/011/6336 959, Fax: + 39/011/6336931 \\ paolo.mulatero@unito.it
}

\section{ABSTRACT}

Primary aldosteronism (PA) was first reported by Jerome W. Conn in 1954 when it was considered a rare disorder, only suspected in cases of hypertension and spontaneous hypokalemia. Over the last 30 years, with the wide application of the plasma aldosterone to plasma renin activity ratio as screening test, the clinical spectrum of PA has dramatically changed. Different studies displayed significant differences in term of patients investigated, diagnostic criteria and hormonal assays; however, large prospective studies with robust diagnostic criteria indicated that the prevalence of PA is around $6 \%$ of the general hypertensive population and $11 \%$ of the patients referred to hypertension centers. In light of these epidemiological studies, the Endocrine Society Guideline recommends the screening for PA of around $50 \%$ of patients with hypertension, and identifies the categories of patients at high risk for the disease. However, clinical data obtained from "real-life" show that the screening rate is much lower and PA remains an under-diagnosed and under-treated cause of secondary hypertension with an associated increased risk of cardio- and cerebrovascular mortality and morbidity.

\section{Introduction}

Primary aldosteronism (PA) is an overlooked but frequent cause of secondary hypertension. A timely diagnosis, followed by a targeted treatment are important to reduce the risk of cardio- and cerebrovascular complications associated with aldosterone excess in affected patients [1-3].

In 2008, the Endocrine Society (ES) Guideline defined categories of patients at high risk for PA, that should undergo a screening test [4]. Later, the updated version of the Guideline [5] further expanded these categories, to include around $50 \%$ of the patients with arterial hypertension. In a recent survey, 500 general practitioners (250 in Italy and 250 in Germany) were asked to complete a questionnaire on the management of patients with arterial hypertension and the diagnosis of PA. Disappointingly, the results of the study showed that only $7-8 \%$ of patients with hypertension were screened for PA and, as a consequence, the prevalence of the diagnosis of the disease was in view of the participants only $1 \%$ in Italy and $2 \%$ in Germany [6], far below the figures reported in primary care studies $[7,8]$. Similarly, a recent analysis conducted on information available from the Database of the Emilia-Romagna (Northern Italy) Health Service, showed that in the period 20002015 , only $1.9 \%$ of the expected cases of PA were diagnosed and $1 \%$ of the expected adrenalectomies were performed [9]. Taken together, these data clearly indicated that, despite significant advances in its clinical management, PA remains a largely unrecognized and undertreated disease. The PASO (primary aldosteronism surgery outcome) study [10] highlighted the importance of the early diagnosis of PA: patients with a complete clinical outcome (cure of hypertension) had a duration of hypertension that was half that of patients with partial or absent clinical success. Furthermore, 
the appropriate subtype diagnosis resulted in a relevant success of adrenalectomy for patients with unilateral PA: normalization or a significant reduction in blood pressure was observed in $84 \%$ of the patients and the complete biochemical cure of PA in $94 \%$ [10]. Finally, it has been shown that diagnosis and treatment of PA is also cost-effective [11].

\section{Historical Perspectives}

PA was reported as a new clinical entity for the first time by Jerome W. Conn during his presidential address to the Central Society for Clinical Research in Chicago, Illinois in 1954 [12]. The index case was a 34-year old woman with a 4-year history of hypertension, muscle spasms, temporary paralysis, and weakness associated with severe hypokalemia, mild hypernatremia, and metabolic alkalosis. A bilateral adrenalectomy was planned, but during the surgical intervention a $13 \mathrm{~g}$ adrenal tumor was discovered and resected, sparing the contralateral adrenal. The tumor resection reverted the clinical and metabolic alterations and for the first time a relationship between aldosterone excess and the aforementioned features was established. Conn "temporarily" defined the clinical syndrome primary aldosteronism $[12,13]$.

A few years after its first description, Conn himself predicted the prevalence of PA to be comprised between 10 and $20 \%$ among hypertensive patients $[14,15]$. However, several authors refused Conn's hypothesis and, until the ' 90 s, PA was considered to be a rare disorder, accounting for less than $1 \%$ of all hypertensives [16-19].

Similarly, PA was believed to be a relatively benign condition [20], always associated with spontaneous hypokalemia [21, 22]. The consideration of PA as a benign condition originated from studies by the group of John Laragh who showed that the occurrence of cardiovascular events in patients with essential hypertension was directly correlated with renin levels $[23,24]$, that is, patients with low renin displayed a low risk for events.

Meanwhile in 1973, Buhler et al. used for the first time the plasma aldosterone to plasma renin activity ratio (ARR) to identify patients with low renin hypertension [25] and, three years later, Dunn and Espiner applied the ARR for PA diagnosis with and without fludrocortisone suppression [26]. However, the new era for PA began in 1981, when Hiramatsu et al. [27] investigated the role of ARR in 348 hypertensive individuals to identify patients with aldosterone producing adenoma (APA), showing a prevalence of $2.6 \%$. In the following years, PA screening was progressively extended to patients with normokalemic resistant hypertension and later on to relatively unselected populations, leading to a 15 -fold increase in prevalence [28-30]. Intriguingly, in the cohort of patients with hypertension investigated by Hiramatsu, $67 \%$ of those with a final diagnosis of APA displayed normal potassium levels [27] and over the following years the proportion of patients with normokalemic PA progressively increased to 63-91\% [30]. The widespread use of ARR progressively changed the relative reported prevalence of the two main PA subtypes, APA and bilateral adrenal hyperplasia (BAH) [30]. In 1998 aldosteronoma was still considered the most common cause of PA and BAH was thought to account for no more than $20-30 \%$ of all cases [19]. On the contrary, recent studies indicate that the prevalence of APA among patients with PA ranges from 28 to $50 \%$ in centers that perform adrenal venous sampling (AVS) for subtype diagnosis $[8,30]$.

\section{Prevalence of Primary Aldosteronism in Primary Care Units}

Prevalence of PA in apparently unselected patients with hypertension was investigated for the first time by Gordon et al. [31] in 1993. Several other studies were subsequently conducted, reporting a wide heterogeneity in the prevalence of PA, ranging between 3.2 and $12.7 \%$ ( $>$ Fig. 1). The majority of these studies were published before the release of the first edition of the Endocrine Society Guideline for the treatment and diagnosis of PA in 2008 [4], which can partially explain the wide variation reported for the prevalence of PA, due to the different criteria used for patient selection and diagnosis.

In particular, some studies excluded patients with hypertension and hypokalemia [35-37] or severe hypertension [37] thereby underestimating the prevalence of PA; other studies only investigated newly diagnosed patients with hypertension $[34,40]$ or included relatively young patients with mild forms of hypertension [8], and one study included patients with normotension [39].

The choice of the screening test varied widely: in some studies, the ARR was used alone, in others the plasma aldosterone concentration was taken into account and in other studies a screening test was not performed, evaluating PA prevalence directly with a confirmatory test $[7,35]$. The choice of the confirmatory test also varied: fludrocortisone suppression tests and intravenous saline load tests (SLT) were the most frequently used, while oral SLT and captopril tests were used less frequently [7]. In the PATO (primary aldosteronism in Torino) study, the choice between intravenous SLT and captopril test was made individually for each patient, based on clinical characteristics and comorbidities [8]. Finally, only two studies performed AVS systematically for subtype diagnosis $[8,40]$.

Excluding studies in which only normokalemic hypertensives were selected [35, 37] or a screening test was not performed [35], the variability in PA prevalence is reduced to $3.7-11.5 \%$. The prevalence range is further reduced to $4.6-8.5 \%$, if studies with a small sample size are not considered [31,39]. This prevalence is similar to that reported by the recent PATO study (5.9\%) that included 1672 patients prospectively recruited from primary care in Torino, Italy [8].

Hypokalemia was detected in $24.6-37.5 \%$ of patients with confirmed PA $[8,34,38]$, with the exception of the study by Mosso et al., which reported significantly lower figures (2.7\%) [33].

Prevalence of PA according to the severity of hypertension was evaluated in two studies reporting a PA prevalence of $2.0-3.9 \%$ in stage $1,8.0-9.7 \%$ in stage 2 , and $11.8-13.2 \%$ in stage 3 [8, 33]. Finally, when AVS was systematically performed, prevalence of APA was $27 \%$ and $\mathrm{BAH} 65-73 \%[8,40]$. It should be underlined that, even in patients with PA from primary care, the prevalence of target organ damage and cardiovascular events was significantly higher than for patients with essential hypertension [8]. 


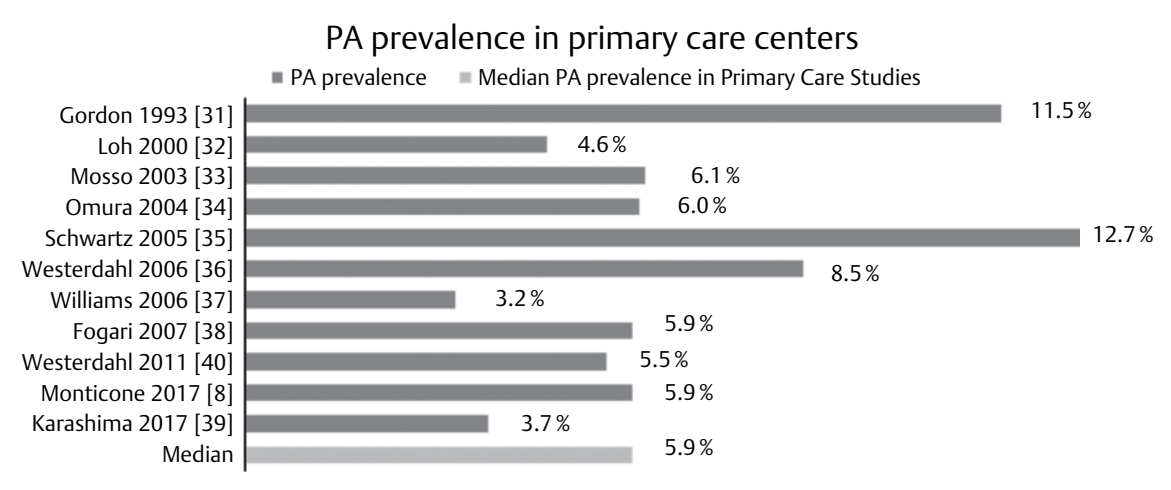

- Fig. 1 Prevalence of PA in studies including patients with hypertension selected in Primary Care and the median prevalence rate of PA.

\section{Prevalence of Primary Aldosteronism in Referral Centers}

In a recent meta-analysis of 30 studies that included 36614 patients, Käyser et al. [7] reported a wide heterogeneity in PA prevalence among selected patients with hypertension from referral centers, ranging from $0.7 \%$ to $29.8 \%$ ( $\triangleright$ Fig. 2). Many differences in terms of patient selection, study design, screening test and confirmatory testing for PA were identified across studies as expected. A meta-regression analysis identified a higher prevalence of PA in studies published after 2000 , in studies with consecutive patient inclusion, when no screening test was performed and when the study objective was to assess the prevalence of secondary hypertension [7].

A retrospective analysis, evaluating PA diagnosis before and after ARR application in 5 referral centers worldwide, demonstrated that hypokalemia affects from $9 \%$ to $37 \%$ of patients with PA and $\mathrm{BAH}$ is the most common subtype. In fact, in centers that systematically performed AVS, APA is diagnosed in $28-50 \%$ of patients with confirmed PA [30].

In referral centers PA prevalence also progressively increases with the severity of arterial hypertension, from $6.6 \%$ in stage 1 , to $19 \%$ in stage 3 [52]. Patients with resistant hypertension demonstrated the highest prevalence of PA, up to $20 \%$ in some centers [66]. Hypokalemia is more frequent in this subgroup of patients, ranging from $45.6 \%$ to $72 \%$ [66], in agreement with a more severe phenotype.

Calhoun et al. evaluated PA prevalence among African American and Caucasian patients with resistant hypertension in North America, and confirmed that plasma renin activity (PRA) and aldosterone are lower in African Americans; however, this finding does not reflect significant differences in PA prevalence [66]. A high prevalence of PA among patients with resistant hypertension was also found in Chinese (7.1\%) [62], European (11.3-15.2\%) [53,63], and South American (5.9\%) populations [58]. Differences in reported prevalence among these populations could be due to ethnic variability or to differences in patient selection and diagnostic workup.

\section{Prevalence of Primary Aldosteronism in Special Population}

\section{Osbstructive sleep apnoea}

Other than the traditional categories at high risk for the disease, the 2016 ES Guideline recommends the screening of patients with hypertension with obstructive sleep apnoea (OSA) for PA [5].

Patients with OSA display high levels of serum aldosterone [67] and there is a correlation between aldosterone levels and worsening of apnoea-hypopnea index (AHI) $[68,69]$. Aldosterone excess may play a pivotal role in the pathophysiology of OSA and, on the other hand, OSA seems to increase aldosterone levels by activation of the renin-angiotensin-aldosterone system; this excess appears to be partially reversible with continuous positive airway pressure in patients with high aldosterone level at baseline [69]. PA and OSA also share obesity as a common underlying condition: obesity is common in OSA patients and increased adipokines such as leptin, which have been shown to increase aldosterone secretion [70], could be responsible for the augmented aldosterone production independent from the renin-angiotensin system activation.

Sim et al. demonstrated a higher prevalence of OSA in hypertensive patients with an elevated ARR compared to patients with a low ARR [71]. However, only one study has directly compared the prevalence of PA in patients with hypertension with and without OSA [56]. The study was performed in a tertiary referral center and a PA prevalence of $34 \%$ was observed in patients with arterial hypertension with OSA (18 of 53 patients), compared with a prevalence of $10 \%$ among patients with hypertension without sleep disorders. All patients with PA underwent computed tomography (CT) imaging and AVS for subtype testing: $28 \%$ of them displayed a unilateral form and $72 \%$ a bilateral form [56].

\section{Diabetes}

The association between PA and impaired carbohydrate tolerance was first described by Conn in 1965 [72]. Subsequently it was shown that patients with PA present a higher rate of metabolic syndrome $[8,73,74]$, higher levels of plasma fasting glucose, and a 


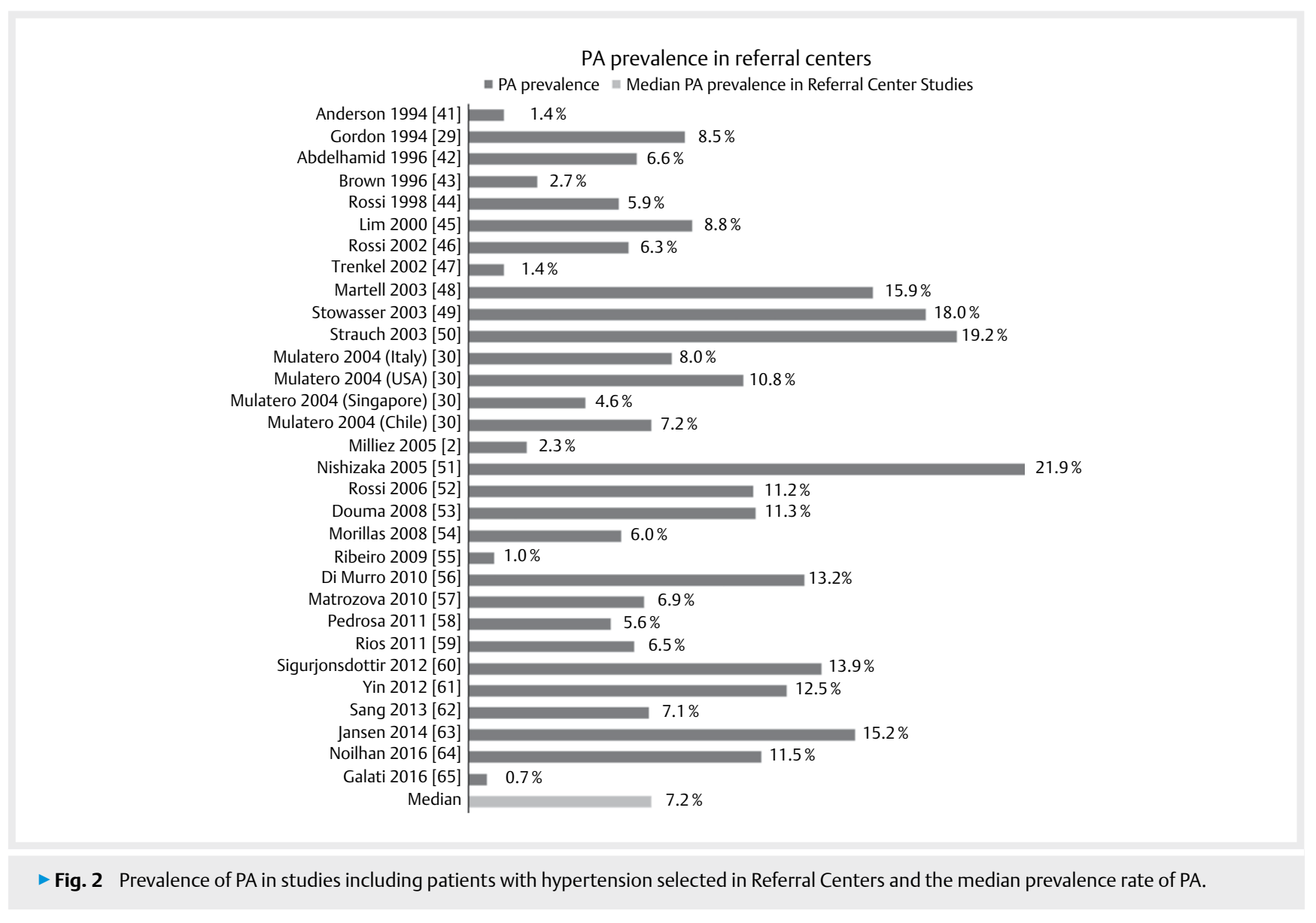

higher probability of developing type 2 diabetes compared with patients with essential hypertension $[1,74]$. This is consistent with the experimental findings showing that aldosterone affects glucose metabolism and promotes insulin resistance $[75,76]$.

Over the last 10 years many studies investigated the prevalence of PA in patients with type 2 diabetes. Two studies, performed in different ethnic populations, showed similar prevalence data: $14 \%$ in a population composed predominantly of patients of African-American descent and $13 \%$ among patients with hypertension from Asia [77, 78]. Hypokalemia was present in $46 \%$ of the patients and, when AVS was performed systematically, a unilateral form of PA was demonstrated in $61.5 \%$ of cases [78].

Murase et al. [79] demonstrated a PA prevalence of $11.3 \%$ in a diabetic population of 124 hospitalized patients. Of note, PA patients displayed a shorter history of diabetes, compared to patients with essential hypertension, and most of them were diagnosed with hypertension before than with diabetes [79]. This sequence of events strengthens the hypothesis of a causal role for PA in the development of diabetes.

In contrast with previous studies, Tancredi et al. [80] recently reported a low prevalence of PA among patients with type 2 diabetes $(0.93 \%)$. However, the study included both patients who were normotensive and those who were hypertensive (the mean systolic and diastolic arterial pressure were $137 \mathrm{mmHg}$ and $77 \mathrm{mmHg}$ respectively); patients treated with MRA or potassium-sparing diuretics ( $4.7 \%$ of the total cohort) were excluded and many patients with a positive screening test for PA did not undergo further evaluation because of severe comorbidities or old age without clinical signs of PA [80]. These limitations probably affected the final results and underestimated the real prevalence of PA.

\section{Atrial fibrillation}

Patients with PA display a risk of atrial flutter or fibrillation 7-12fold higher than patients with $\mathrm{EH}[2,81]$, and generally display an increased risk of sustained arrhythmias (including sustained ventricular tachycardia and ventricular fibrillation) [1].

Compelling evidence suggests that aldosterone exerts a crucial role in the pathophysiology of atrial fibrillation (AF), promoting cardiac hypertrophy, fibrosis, and inflammation with consequent diastolic dysfunction and left atrium dilatation. These cardiac alterations have been clearly associated with the development of AF in the Framingham Heart Study [82] and several other studies over the following years [83]. In an animal model, aldosterone plays a pro-arrhythmogenic role at the atrial level by altering the cardiac electric properties [84].

Despite evidence of a strict link between AF and PA, no prospective studies, evaluating prevalence of PA in patients affected by $A F$ are currently available. Nevertheless, the demonstration of a high prevalence of $\mathrm{PA}$ in patients with $\mathrm{AF}$ it is important to address these patients to a systematic screening for PA. The ongoing PAPPHY (prospective appraisal of the prevalence of primary aldosteronism in hypertensive patients presenting with atrial flutter or fibrillation) 
study, evaluating PA prevalence in patients with AF diagnosis, will provide further information about this issue [85].

\section{Patients with Arterial Hypertension and Adrenal Incidentaloma}

Adrenal incidentalomas are present in $0.5-2.0 \%$ of patients undergoing an abdominal CT scan with a prevalence that progressively increases with age up to $7 \%$ by 70 years. Conversely, the prevalence of incidentalomas is very low in children, adolescents, and young adults (less than $1 \%$ ) [86]. In clinical studies, the major part of adrenal incidentalomas are non-functioning adrenal adenomas (almost $75 \%), 12 \%$ are cortisol-secreting adenomas, $7 \%$ pheochromocytomas, $8 \%$ adrenal carcinomas (almost all with a diameter $\geq 4 \mathrm{~cm}$ ), $5 \%$ metastasis, and only $2.5 \%$ are aldosterone producing adenomas (APA) [87]. The Endocrine Society guideline recommends that PA should be considered in all patients with an incidentally discovered adrenal mass and arterial hypertension [4, 5].

\section{Conclusions}

Although over the last 20 years many efforts were made to identify the actual prevalence of PA among the general population with hypertension or among patients referred to hypertension units, knowledge is still lacking on the prevalence of PA in selected populations. It is therefore desirable that future studies are addressed to specific populations to further expand the categories of patients with hypertension at high risk of PA to thus reduce the possibility of missing or delaying a diagnosis.

In conclusion, the lessons from the recent PATO and PASO studies, together with increasing evidence from the preceding decade of clinical studies, clearly indicate that most if not all patients with hypertension should be screened for PA and should be screened early, before the occurrence of the detrimental effects of aldosterone on kidney, heart, and vessels.

\section{Conflict of Interest}

The authors declare that they have no conflict of interest.

\section{References}

[1] Mulatero P, Monticone S, Bertello C, Viola A, Tizzani D, lannaccone A, Crudo V, Burrello J, Milan A, Rabbia F, Veglio F. Long-term cardio- and cerebrovascular events in patients with primary aldosteronism. J Clin Endocrinol Metab 2013; 98: 4826-4833

[2] Milliez P, Girerd X, Plouin P-F, Blacher ], Safar ME, Mourad J-J. Evidence for an increased rate of cardiovascular events in patients with primary aldosteronism. J Am Coll Cardiol 2005; 45: 1243-1248

[3] Prejbisz A, Warchoł-Celińska E, Lenders JWM, Januszewicz A. Cardiovascular risk in primary hyperaldosteronism. Horm Metab Res 2015; 47: 973-980

[4] Funder JW, Carey RM, Fardella C, Gomez-Sanchez CE, Mantero F, Stowasser M, Young WF Jr., Montori VM.Endocrine Society. Case detection, diagnosis, and treatment of patients with primary aldosteronism: an endocrine society clinical practice guideline. J Clin Endocrinol Metab 2008: 93: 3266-3281
[5] Funder JW, Carey RM, Mantero F, Murad MH, Reincke M, Shibata H, Stowasser M, Young WF. The management of primary aldosteronism: case detection, diagnosis, and treatment: An endocrine society clinical practice guideline. J Clin Endocrinol Metab 2016; 101: 1889-1916

[6] Mulatero P, Monticone S, Burrello J, Veglio F, Williams TA, Funder J. Guidelines for primary aldosteronism: Uptake by primary care physicians in Europe. J Hypertens 2016; 34: 2253-2257

[7] Käyser SC, Dekkers T, Groenewoud HJ, van der Wilt G], Carel Bakx J, van der Wel MC, Hermus AR, Lenders JW, Deinum J. Study heterogeneity and estimation of prevalence of primary aldosteronism: A systematic review and meta-regression analysis. J Clin Endocrino Metab 2016; 101: 2826-2835

[8] Monticone S, Burrello J, Tizzani D, Bertello C, Viola A, Buffolo F, Gabetti L, Mengozzi G, Williams TA, Rabbia F, Veglio F, Mulatero P. Prevalence and clinical manifestations of primary aldosteronism encountered in primary care practice. J Am Coll Cardiol 2017; 69: 1811-1820

[9] Rossi E, Perazzoli F, Negro A, Magnani A. Diagnostic rate of primary aldosteronism in Emilia-Romagna, Northern Italy, during 16 years (2000-2015). J Hypertens 2017; 35: 1691-1697

[10] Williams TA, JWM Lenders, Mulatero P, Burrello ], Rottenkolber M, Adolf C, Satoh F, Amar L, Quinkler M, Deinum J, Beuschlein F, Kitamoto KK, Pham U, Morimoto R, Umakoshi H, Prejbisz A, Kocjan T, Naruse M, Stowasser M, Nishikawa T, Young WF, Gomez-Sanchez CE, Funder JW, Reincke M.Primary Aldosteronism Surgery Outcome (PASO) investigators. Outcomes after adrenalectomy for unilateral primary aldosteronism: An international consensus on outcome measures and analysis of remission rates in an international cohort. Lancet Diabetes Endocrinol 2017; 5: 689-699

[11] Sato M, Morimoto R, Seiji K, Iwakura Y, Ono Y, Kudo M, Satoh F, Ito S, Ishibashi T, Takase K. Cost-effectiveness analysis of the diagnosis and treatment of primary aldosteronism in Japan. Horm Metab Res 2015; 47: 826-832

[12] Conn JW. Presidential address. I. Painting background. II. Primary aldosteronism, a new clinical syndrome. J Lab Clin Med 1955; 45: 3-17

[13] Gittler RD, Fajans SS. Primary aldosteronism (Conn's syndrome). J Clin Endocrinol Metab 1995; 80: 3438-3441

[14] Conn JW, Cohen EL, Rovner DR. Suppression of plasma renin activity in primary aldosteronism. JAMA 1964; 190: 213-221

[15] Conn JW, Knopf RF, Nesbit RM. Clinical characteristics of primary aldosteronism from an analysis of 145 cases. Am J Surg 1964; 107: 159-172

[16] Kaplan NM. Hypokalemia in the hypertensive patient, with observations on the incidence of primary aldosteronism. Ann Intern Med 1967; 66: 1079-1090

[17] Fishman LM, Kuchel O, Liddle GW, Michelakis AM, Gordon RD, Chick WT. Incidence of primary aldosteronism uncomplicated „essential“ hypertension. A prospective study with elevated aldosterone secretion and suppressed plasma renin activity used as diagnostic criteria. JAMA 1968; 205: 497-502

[18] Kaplan NM. Diagnostics and techniques. Curr Opin Nephrol Hypertens 1994; 3: 627-628

[19] Ganguly A. Primary aldosteronism. N Engl ] Med 1998; 339: 1828-1834

[20] Kaplan NM. Commentary on incidence of primary aldosteronism: current estimations based on objective data. Arch Intern Med 1969; 123: $152-154$

[21] Ledingham JGC. Secondary hypertension. In: Oxford textbook of medicine 2. Oxford University Press; 1987: 13382-13397

[22] Biglieri EG, Kater CE. Internal Medicine. In: Disorder of the adrenal cortex. Brown 1991; 2188-2207

[23] Alderman MH, Madhavan S, Ooi WL, Cohen H, Sealey JE, Laragh JH. Association of the renin-sodium profile with the risk of myocardial infarction in patients with hypertension. N Engl J Med 1991; 324: 1098-1104 
[24] Brunner HR, Laragh JH, Baer L, Newton MA, Goodwin FT, Krakoff LR, Bard RH, Bühler FR. Essential hypertension: Renin and aldosterone, heart attack and stroke. N Engl J Med 1972; 286: 441-449

[25] Bühler FR, Laragh JH, Sealey JE, Brunner HR. Plasma aldosterone-renin interrelationships in various forms of essential hypertension. Studies using a rapid assay of plasma aldosterone. Am J Cardiol 1973; 32: 554-561

[26] Dunn PJ, Espiner EA. Outpatient screening tests for primary aldosteronism. Aust N Z J Med 1976; 6: 131-135

[27] Hiramatsu K, Yamada T, Yukimura Y, Komiya I, Ichikawa K, Ishihara M, Nagata $\mathrm{H}$, Izumiyama T. A screening test to identify aldosterone-producing adenoma by measuring plasma renin activity. Results in hypertensive patients. Arch Intern Med 1981; 141: 1589-1593

[28] Gordon RD, Klemm SA, Stowasser M, Tunny T], Storie WJ, Rutherford JC. How common is primary aldosteronism? Is it the most frequent cause of curable hypertension? J Hypertens Suppl 1993; 11: S310-S311

[29] Gordon RD, Stowasser M, Tunny TJ, Klemm SA, Rutherford JC. High incidence of primary aldosteronism in 199 patients referred with hypertension. Clin Exp Pharmacol Physiol 1994; 21: 315-318

[30] Mulatero P, Stowasser M, Loh K-C, Fardella CE, Gordon RD, Mosso L, Gomez-Sanchez CE, Veglio F, Young WF Jr. Increased diagnosis of primary aldosteronism, including surgically correctable forms, in centers from five continents. J Clin Endocrinol Metab 2004; 89: 1045-1050

[31] Gordon RD, Ziesak MD, Tunny T], Stowasser M, Klemm SA. Evidence that primary aldosteronism may not be uncommon: $12 \%$ incidence among antihypertensive drug trial volunteers. Clin Exp Pharmacol Physiol 1993; 20: 296-298

[32] Loh KC, Koay ES, Khaw MC, Emmanuel SC, Young WF Jr. Prevalence of primary aldosteronism among Asian hypertensive patients in Singapore. J Clin Endocrinol Metab 2000; 85: 2854-2859

[33] Mosso L, Carvajal C, González A, Barraza A, Avila F, Montero ], Huete A, Gederlini A, Fardella CE. Primary aldosteronism and hypertensive disease. Hypertension 2003; 42: 161-165

[34] Omura M, Saito J, Yamaguchi K, Kakuta Y, Nishikawa T. Prospective study on the prevalence of secondary hypertension among hypertensive patients visiting a general outpatient clinic in Japan. Hypertens Res 2004; 27: 193-202

[35] Schwartz GL, Turner ST. Screening for primary aldosteronism in essential hypertension: diagnostic accuracy of the ratio of plasma aldosterone concentration to plasma renin activity. Clin Chem 2005; 51: 386-394

[36] Westerdahl C, Bergenfelz A, Isaksson A, Wihl A, Nerbrand C, Valdemarsson $S$. High frequency of primary hyperaldosteronism among hypertensive patients from a primary care area in Sweden. Scand J Prim Health Care 2006; 24: 154-159

[37] Williams JS, Williams GH, Raji A, Jeunemaitre X, Brown N], Hopkins PN, Conlin PR. Prevalence of primary hyperaldosteronism in mild to moderate hypertension without hypokalaemia. J Hum Hypertens 2006; 20: 129-136

[38] Fogari R, Preti P, Zoppi A, Rinaldi A, Fogari E, Mugellini A. Prevalence of primary aldosteronism among unselected hypertensive patients: A prospective study based on the use of an aldosterone/renin ratio above 25 as a screening test. Hypertens Res 2007; 30: 111-117

[39] Karashima S, Kometani M, Tsujiguchi H, Asakura H, Nakano S, Usukura M, Mori S, Ohe M, Sawamura T, Okuda R, Hara A, Takamura T, Yamagishi M, Nakamura H, Takeda Y, Yoneda T. Prevalence of primary aldosteronism without hypertension in the general population: Results in Shika study. Clin Exp Hypertens 2017, doi:10.1080/10641963.2017 .1339072 [Epub ahead of print]

[40] Westerdahl C, Bergenfelz A, Isaksson A, Nerbrand C, Valdemarsson S. Primary aldosteronism among newly diagnosed and untreated hypertensive patients in a Swedish primary care area. Scand J Prim Health Care 2011; 29: 57-62
[41] Anderson GH, Blakeman N, Streeten DH. The effect of age on prevalence of secondary forms of hypertension in 4429 consecutively referred patients. J Hypertens 1994; 12: 609-615

[42] Abdelhamid S, Muller-Lobeck H, Pahl S, Remberger K, Bonhof JA, Walb D, Rockel A. Prevalence of adrenal and extra-adrenal Conn syndrome in hypertensive patients. Arch Intern Med 1996; 156: 1190-1195

[43] Brown MA, Cramp HA, Zammit VC, Whitworth JA. Primary hyperaldosteronism: a missed diagnosis in „essential hypertensives“? Aust N Z J Med 1996; 26: 533-538

[44] Rossi GP, Rossi E, Pavan E, Rosati N, Zecchel R, Semplicini A, Perazzoli F, Pessina AC. Screening for primary aldosteronism with a logistic multivariate discriminant analysis. Clin Endocrinol Oxf 1998; 49: 713-723

[45] Lim PO, Dow E, Brennan G, Jung RT, MacDonald TM. High prevalence of primary aldosteronism in the Tayside hypertension clinic population. J Hum Hypertens 2000; 14: 311-315

[46] Rossi E, Regolisti G, Negro A, Sani C, Davoli S, Perazzoli F. High prevalence of primary aldosteronism using postcaptopril plasma aldosterone to renin ratio as a screening test among Italian hypertensives. Am J Hypertens 2002; 15: 896-902

[47] Trenkel S, Seifarth C, Schobel H, Hahn EG, Hensen J. Ratio of serum aldosterone to plasma renin concentration in essential hypertension and primary aldosteronism. Exp Clin Endocrinol Diabetes Off J Ger Soc Endocrinol Ger Diabetes Assoc 2002; 110: 80-85

[48] Martell N, Rodriguez-Cerrillo M, Grobbee DE, López-Eady MD, Fernández-Pinilla C, Avila M, Fernández-Cruz A, Luque M. High prevalence of secondary hypertension and insulin resistance in patients with refractory hypertension. Blood Press 2003; 12: 149-154

[49] Stowasser M, Gordon RD, Gunasekera TG, Cowley DC, Ward G, Archibald C, Smithers BM. High rate of detection of primary aldosteronism, including surgically treatable forms, after „non-selective" screening of hypertensive patients. J Hypertens 2003; 21: 2149-2157

[50] Strauch B, Zelinka T, Hampf M, Bernhardt R, Widimsky J Jr.. Prevalence of primary hyperaldosteronism in moderate to severe hypertension in the Central Europe region. J Hum Hypertens 2003; 17: 349-352

[51] Nishizaka MK, Pratt-Ubunama M, Zaman MA, Cofield S, Calhoun DA. Validity of plasma aldosterone-to-renin activity ratio in African American and white subjects with resistant hypertension. Am J Hypertens 2005; 18: 805-812

[52] Rossi GP, Bernini G, Caliumi C, Desideri G, Fabris B, Ferri C, Ganzaroli C, Giacchetti G, Letizia C, Maccario M, Mallamaci F, Mannelli M, Mattarello MJ, Moretti A, Palumbo G, Parenti G, Porteri E, Semplicini A, Rizzoni D, Rossi E, Boscaro M, Pessina AC, Mantero F. A prospective study of the prevalence of primary aldosteronism in 1,125 hypertensive patients. J Am Coll Cardiol 2006; 48: 2293-2300

[53] Douma S, Petidis K, Doumas M, Papaefthimiou P, Triantafyllou A, Kartali N, Papadopoulos N, Vogiatzis K, Zamboulis C. Prevalence of primary hyperaldosteronism in resistant hypertension: A retrospective observational study. Lancet 2008; 371: 1921-1926

[54] Morillas P, Castillo J, Quiles ], Núñez D, Guillén S, Bertomeu-González $\mathrm{V}$, Pomares F, Bertomeu V. Prevalence of primary aldosteronism in hypertensive patients and its effect on the heart. Rev Esp Cardiol 2008; 61: 418-421

[55] Ribeiro MJS, Figueiredo Neto JA, de Memória EV, Lopes M de C, Faria M dos S, Salgado Filho N, de Oliveira TC. Prevalence of primary hyperaldosteronism in a systemic arterial hypertension league. Arq Bras Cardiol 2009; 92: 39-45

[56] Di Murro A, Petramala L, Cotesta D, Zinnamosca L, Crescenzi E, Marinelli C, Saponara M, Letizia C. Renin-angiotensin-aldosterone system in patients with sleep apnoea: Prevalence of primary aldosteronism. J Renin-Angiotensin-Aldosterone Syst JRAAS 2010; 11 : $165-172$ 
[57] Matrozova JA, Zacharieva SZ, Kirilov GG, Boyanov MA. Prevalence of primary aldosteronism among bulgarian hypertensive patients. Cent Eur J Med 2010; 5: 399-405

[58] Pedrosa RP, Drager LF, Gonzaga CC, Sousa MG, de Paula LKG, Amaro ACS, Amodeo C, Bortolotto LA, Krieger EM, Bradley TD, Lorenzi-Filho G. Obstructive sleep apnea: The most common secondary cause of hypertension associated with resistant hypertension. Hypertension 2011; 58: 811-817

[59] Ríos MC, Izquierdo A, Sotelo M, Honnorat E, Rodríguez Cuimbra S, Catay E, Popescu BM. Aldosterone/renin ratio in the diagnosis of primary aldosteronism. Medicina (Mex) 2011; 71: 525-530

[60] Sigurjonsdottir HA, Gronowitz M, Andersson O, Eggertsen R, Herlitz H, Sakinis A, Wangberg B, Johannsson G. Unilateral adrenal hyperplasia is a usual cause of primary hyperaldosteronism. Results from a Swedish screening study. BMC Endocr Disord 2012; 12: 17

[61] Yin G, Zhang S, Yan L, Wu M, Xu M, Li F, Cheng H. Effect of age on aldosterone/renin ratio (ARR) and comparison of screening accuracy of ARR plus elevated serum aldosterone concentration for primary aldosteronism screening in different age groups. Endocrine 2012; 42: 182-189

[62] Sang X, Jiang Y, Wang W, Yan L, Zhao J, Peng Y, Gu W, Chen G, Liu W, Ning $G$. Prevalence of and risk factors for primary aldosteronism among patients with resistant hypertension in China. J Hypertens 2013; 31: 1465-1471

[63] Jansen PM, van den Born B-JH, Frenkel W], de Bruijne ELE, Deinum J, Kerstens MN, Smulders YM, Woittiez AJ, Wijbenga JAM, Zietse R, AH] Danser, van den Meiracker AH. Test characteristics of the aldosterone-to-renin ratio as a screening test for primary aldosteronism. J Hypertens 2014; 32: 115-126

[64] Noilhan C, Barigou M, Bieler L, Amar J, Chamontin B, Bouhanick B. Causes of secondary hypertension in the young population: $A$ monocentric study. Ann Cardiol Angeiol (Paris) 2016; 65: 159-164

[65] Galati S-J, Cheesman KC, Springer-Miller R, Hopkins SM, Krakoff L, Bagiella E, Zhuk RA, Ying TK, Amer C, Boyajian MK, Inabnet WB, Levine AC. Prevalence of primary aldosteronism in an urban hypertensive population. Endocr Pract 2016; 22: 1296-1302

[66] Calhoun DA, Nishizaka MK, Zaman MA, Thakkar RB, Weissmann P. Hyperaldosteronism among black and white subjects with resistant hypertension. Hypertension 2002; 40: 892-896

[67] Goodfriend TL, Calhoun DA. Resistant hypertension, obesity, sleep apnea, and aldosterone: Theory and therapy. Hypertension 2004; 43: 518-524

[68] Gonzaga CC, Gaddam KK, Ahmed MI, Pimenta E, Thomas S], Harding SM, Oparil S, Cofield SS, Calhoun DA. Severity of obstructive sleep apnea is related to aldosterone status in subjects with resistant hypertension. J Clin Sleep Med 2010; 6: 363-368

[69] Barceló A, Piérola J, Esquinas C, de la Peña M, Arqué M, Alonso-Fernán$\operatorname{dez} A$, Bauçà JM, Robles J, Barceló B, Barbé F. Relationship between aldosterone and the metabolic syndrome in patients with obstructive sleep apnea hypopnea syndrome: effect of continuous positive airway pressure treatment. PloS One 2014; 9: e84362

[70] Huby A-C, Antonova G, Groenendyk J, Gomez-Sanchez CE, Bollag WB, Filosa JA, Belin de Chantemèle EJ. Adipocyte-derived hormone leptin is a direct regulator of aldosterone secretion, which promotes endothelial dysfunction and cardiac fibrosis. Circulation 2015; 132: 2134-2145

[71] Sim J], Yan EH, Liu ILA, Rasgon SA, Kalantar-Zadeh K, Calhoun DA, Derose SF. Positive relationship of sleep apnea to hyperaldosteronism in an ethnically diverse population. J Hypertens 2011; 29: 1553-1559

[72] Conn JW. Hypertension, the potassium ion and impaired carbohydrate tolerance. N Engl J Med 1965; 273: 1135-1143
[73] Fallo F, Veglio F, Bertello C, Sonino N, Della Mea P, Ermani M, Rabbia F, Federspil G, Mulatero P. Prevalence and characteristics of the metabolic syndrome in primary aldosteronism. J Clin Endocrinol Metab 2006; 91: 454-459

[74] Reincke M, Meisinger C, Holle R, Quinkler M, Hahner S, Beuschlein F, Bidlingmaier M, Seissler J, Endres S. Participants of the German Conn's Registry. Is primary aldosteronism associated with diabetes mellitus? Results of the German Conn's Registry. Horm Metab Res 2010; 42: 435-439

[75] Williams TA, Monticone S, Urbanet R, Bertello C, Giraudo G, Vettor R, Fallo F, Veglio F, Mulatero P. Genes implicated in insulin resistance are down-regulated in primary aldosteronism patients. Mol Cell Endocrinol 2012; 355: 162-168

[76] Whaley-Connell A, Sowers JR. Aldosterone and Risk for Insulin Resistance. Hypertension 2011; 58: 998-1000

[77] Umpierrez GE, Cantey P, Smiley D, Palacio A, Temponi D, Luster K, Chapman A. Primary aldosteronism in diabetic subjects with resistant hypertension. Diabetes Care 2007; 30: 1699-1703

[78] Mukherjee J], Khoo CM, Thai AC, Chionh SB, Pin L, Lee KO. Type 2 diabetic patients with resistant hypertension should be screened for primary aldosteronism. Diabetes Vasc Dis Res 2010; 7: 6-13

[79] Murase K, Nagaishi R, Takenoshita H, Nomiyama T, Akehi Y, Yanase T. Prevalence and clinical characteristics of primary aldosteronism in Japanese patients with type 2 diabetes mellitus and hypertension. Endocr J 2013; 60: 967-976

[80] Tancredi M, Johannsson G, Eliasson B, Eggertsen R, Lindblad U, Dahlqvist $\mathrm{S}$, Imberg $\mathrm{H}$, Lind M. Prevalence of primary aldosteronism among patients with type 2 diabetes. Clin Endocrinol (Oxf) 2017; 87: 233-241

[81] Rossi GP, Cesari M, Cuspidi C, Maiolino G, Cicala MV, Bisogni V, Mantero F, Pessina AC. Long-term control of arterial hypertension and regression of left ventricular hypertrophy with treatment of primary aldosteronism. Hypertension 2013; 62: 62-69

[82] Kannel WB, Wolf PA, Benjamin EJ, Levy D. Prevalence, incidence, prognosis, and predisposing conditions for atrial fibrillation: population-based estimates. Am J Cardiol 1998; 82: 2N-9N

[83] Seccia TM, Caroccia B, Adler GK, Maiolino G, Cesari M, Rossi GP. Arterial hypertension, atrial fibrillation, and hyperaldosteronism: The triple trouble. Hypertension 2017; 69: 545-550

[84] Reil J-C, Hohl M, Selejan S, Lipp P, Drautz F, Kazakow A, Münz BM, Müller P, Steendijk P, Reil G-H, Allessie MA, Böhm M, Neuberger H-R. Aldosterone promotes atrial fibrillation. Eur Heart J 2012; 33: 2098-2108

[85] Rossi GP, Seccia TM, Gallina V, Muiesan ML, Leoni L, Pengo M, Ragazzo F, Caielli P, Belfiore A, Bernini G, Cipollone F, Cottone S, Ferri C, Giacchetti G, Grassi G, Letizia C, Maccario M, Olivieri O, Palumbo G, Rizzoni D, Rossi E, Sechi L, Volpe M, Mantero F, Morganti A, Pessina AC. Prospective appraisal of the prevalence of primary aldosteronism in hypertensive patients presenting with atrial flutter or fibrillation (PAPPHY Study): Rationale and study design. J Hum Hypertens 2013; 27: 158-163

[86] Barzon L, Sonino N, Fallo F, Palu G, Boscaro M. Prevalence and natural history of adrenal incidentalomas. Eur J Endocrinol 2003; 149: 273-285

[87] Terzolo M, Stigliano A, Chiodini I, Loli P, Furlani L, Arnaldi G, Reimondo G, Pia A, Toscano V, Zini M, Borretta G, Papini E, Garofalo P, Allolio B, Dupas B, Mantero F, Tabarin A. Italian Association of Clinical Endocrinologists. AME position statement on adrenal incidentaloma. Eur J Endocrinol 2011; 164: 851-870 